\title{
A prospective study of laproscopic paravaginal repair of cystocoele: our experience
}

\author{
Amrapali D. Gosavi ${ }^{1}$, Sanjay P. Dhangar ${ }^{2 *}$
}

\begin{abstract}
${ }^{1}$ Department of Obstetrics and Gynecology, Tambe Hospital, Sangamner, Ahmednagar, Maharashtra, India
${ }^{2}$ Department of Surgery, SMBT IMSRC, Igatpuri, Nashik, Maharashtra, India
\end{abstract}

Received: 09 July 2021

Accepted: 03 August 2021

\section{*Correspondence:}

Dr. Sanjay P. Dhangar,

E-mail: sanjayamrapali18@gmail.com

Copyright: ( $)$ the author(s), publisher and licensee Medip Academy. This is an open-access article distributed under the terms of the Creative Commons Attribution Non-Commercial License, which permits unrestricted non-commercial use, distribution, and reproduction in any medium, provided the original work is properly cited.

\section{ABSTRACT}

Background: Cystocele is diagnosed clinically by vaginal examination approaches using the pelvic organ prolapse quantifications system (POP-Q) of classification. Abdominal and laproscopic are now used due to high failure rate involving the transvaginal repair. Laproscopic repair involves approximation of the vaginal sub-epithelial tissue with the Cooper's ligament using non-absorbable suture.

Methods: This was a prospective observational study from June 2016 to May 2020 over women with symptomatic cystocele of grade $\geq 2$. All patients were preoperatively and post-operatively assessed with quality-of-life questionnaires, pelvic organ prolapse distress inventory-6 (POPDI-6) and urinary distress inventory short form. Clinical examination was done with and without Valsalva maneuver. POP classification was used for grading the prolapse. All patients were assessed for any voiding difficulty after surgery, at one week, three months, six months and 12 months.

Results: The median age of patient was 55.5 years. $90.9 \%$ patients presented with urinary symptoms. $54.5 \%$ patients underwent hysterectomy. The mean blood loss was $55 \mathrm{cc}$. The anatomic cure rate for cystocoele was $100 \%$ in our study in 1 week, 3 months and 6 months post-operatively. There was significant improvement in the quality-of-life scores. Overall, symptomatic relief was seen in $90.9 \%$ patients at first week, $95.4 \%$ at 3 months, $95.4 \%$ at 6 and 12 months follow up. Urinary symptoms were relieved in all patients at first follow up after 7 days, and $95.4 \%$ patients during 3, 6 and 12 months follow up.

Conclusions: Laproscopic paravaginal cystocoele repair is safe, effective and an easy procedure with good results. The procedure is easy to learn and master with low recurrence rates.

Keywords: Cystocoele, Laproscopic cystocoele repair, Paravaginal repair of cystocoele

\section{INTRODUCTION}

Pelvic organ prolapse (POP) is a condition that affects middle and old age females. The lifetime risk of needing a surgical treatment for this condition is around $11 \% .1$ Cystocele is one disabling condition, among other POP problems, for the patients. It is defined as prolapse or 'falling down' of the bladder into the vagina. It is due to the weakness of the bladder and anterior wall of the vagina leading to bladder bulge seen through the vagina. It may or may not be symptomatic. ${ }^{2}$ Symptoms include hesitancy, or increased frequency of urine, urinary incontinence, and vaginal bulge during micturition. It may present with complications like recurrent urinary tract infections and urinary retention. ${ }^{3}$ All this affects the patient's quality of life negatively. ${ }^{4}$ Causes are many but ultimately there is weakening of muscles, fascia, tendons and connective tissue between the bladder and vagina. It is diagnosed clinically by vaginal examination using the pelvic organ prolapse quantifications system (POP-Q) system of classification. ${ }^{5}$ The Baden-Walker Delancey three levels of pelvic support are important to understand the various 
types of cystocoeles. ${ }^{6}$ Halfway scoring system can also be used to classify the descent in a simpler way. ${ }^{7}$ Treatment includes surgical and non-surgical management. Conventional treatment involves transvaginal repair involving anterior colporrhaphy with or without mesh. Abdominal and laproscopic are now used due to high failure rate involving the transvaginal repair. Moreover, there are chances of shortening the vagina. So, to preserve vaginal length and calibre abdominal and laproscopic approaches are preferred. Lateral cystocele comprises around $85-90 \%$ of anterior compartment defects. These defects are corrected by paravaginal repair as compared to the vaginal repair which is considered as inferior method of repair. ${ }^{8}$

\section{METHODS}

We did a prospective observational study in Tambe Hospital, Sangamner, Ahmednagar, Maharashtra, India from June 2016 to May 2020. We included 22 women with symptomatic cystocele $\mathrm{C}$ of grade $\geq 2$. All patients were followed for 12 months after surgery. No patient was lost to follow-up. All patients underwent a laproscopic paravaginal cystocele repair. Associated level 1 and level 3 pelvic floor defects were also repaired at the same time. The study was approved by institutional ethical committee of the hospital. Informed consent was obtained from the patients. The relevant history was taken and recorded. All patients were preoperatively assessed with quality of life (QoL) questionnaires, pelvic organ prolapse distress inventory-6 (POPDI-6) and urinary distress inventory short form (UDI-6). Clinical examination was done with and without Valsalva maneuver. POP-Q classification was used for grading the prolapse.

Patients with pure stress urinary incontinence, pelvic malignancy, pelvic irradiation, neurological disorders, active urinary tract infection (UTI), and all contraindication to laproscopic surgery were excluded.

All patients were given general anaesthesia and antibiotic prophylaxis at the time of induction. All patient were positioned in the modified dorsal lithotomy. Examination under anaesthesia was done and all patients were catheterised. Pneumoperitoneum was created with Veress needle followed by a three/four-port transperitoneal approach in all patients. The primary laproscopic camera port was placed 3-4 $\mathrm{cm}$ above the umbilicus. Two 5-mm ports were placed on the right and left side at the level of umbilicus and additional or 4th port if needed, was placed just above the anterior superior iliac spine.

After doing the diagnostic laproscopy, the peritoneum over the bladder was incised $2 \mathrm{~cm}$ above the dome of the bladder between the two medial umbilical ligaments. The space of Retzius was also identified. On both sides laterally, the Cooper's ligament, obturator internus muscle and the arcus tendineus fascia pelvis were exposed. The paravaginal space was identified. Per vaginum manipulation helped to lift the lateral sulcus and identifying the paravaginal defect. The defect was repaired by three sutures of polypropylene on each side, starting from the distal most subepithelial lateral vaginal wall to the Cooper's ligament. The sutures were tied without tension. The sutures were given alternate on right and left side to maintain equal tension on both sides and to maintain the vaginal symmetry. The reflected peritoneum was then closed with 2-0 vicryl suture. All patients underwent diagnostic cystoscopy after the repair. All patients were allowed orally after six hours of surgery and ambulated later on. The per urethral catheter (PUC) was removed after 48 hours. All patients were assessed for any voiding difficulty after PUC removal and were discharged next day. The patients were followed up at one week, three months, six months and 12 months. We assess the results by symptomatic improvement and the questionnaire. Statistical package for the social sciences (SPSS) was used for data analysis.

\section{RESULTS}

We operated upon 22 patients. The median age of patient was 55.5 years (range 44-70). Median weight of patient in our study was $64.5 \mathrm{~kg}$ (range $38-84$ ). Most common parity was two (range 2-5). Two patients were premenopausal (9\%). Ten patients $(45.4 \%)$ had history of some other previous surgery. Twenty patients $(90.9 \%)$ presented with urinary symptoms. Twelve patients $(54.5 \%)$ underwent hysterectomy. Among these 12 patients, two patients had cystocoele without vault prolapse. Isolated cystocoele repair was done in these patients. Among the remaining ten patients. One patient with vault prolapse underwent simultaneous laproscopic uterosacral colpopexy and remaining nine patients with vault prolapse underwent simultaneous laproscopic sacrocolpopexy.

Two patients had grade II asymptomatic rectocoele. Both were managed conservatively. Six patients had grade $\geq$ II enterocoele. These patients underwent laproscopic Moskowitz repair. There were no major intra-operative complications. The mean blood loss was $55 \mathrm{cc}$ (range 4070). One patient had urinary retention after catheter removal after 48 hours. She also recovered after recatheterisation for 48 hours. The anatomic cure rate for cystocoele was $100 \%$ in our study in 1 week, 3 months and 6 months post-operatively (Table 2). There was significant improvement in the QoL scores (Table 3).

Overall, symptomatic relief was seen in 20 patients $(90.9 \%)$ at first week follow up, in 21 patients $(95.4 \%)$ at 3 months follow up, 21 patients $(95.4 \%)$ at 6 and 12 months follow up. Urinary symptoms were relieved in all patients at first follow up after 7 days, and 21 patients (95.4\%) during 3, 6 and 12 months follow up. One patient had increased urinary frequency, day and night and mild new onset stress urinary incontinence 3 months after cystocoele repair. All her pre-operative symptoms improved after the surgery. On investigation, her urine culture showed growth of Escherichia coli. She was treated with culture specific antibiotics. Her urinary 
frequency improved but stress incontinence remained same even after 12 months of surgery. She was managed conservatively with pelvic floor muscle rehabilitation therapy.

Table 1: Subjective prolapse symptoms, N (\%), preoperatively and during follow-up.

\begin{tabular}{|llllll|}
\hline Symptom & $\begin{array}{l}\text { Preoperative } \\
\mathbf{N}=\mathbf{2 2}(\%)\end{array}$ & $\begin{array}{l}\text { At one week } \\
\mathbf{N}=\mathbf{2 2}(\%)\end{array}$ & $\begin{array}{l}\text { At 3 months } \\
\mathbf{N}=\mathbf{2 2}(\%)\end{array}$ & $\begin{array}{l}\text { At 6 months } \\
\mathbf{N}=\mathbf{2 2}(\%)\end{array}$ & $\begin{array}{l}\text { At 12 months } \\
\mathbf{N}=\mathbf{2 2}(\%)\end{array}$ \\
\hline Mass per vaginum & 22 & 0 & 0 & 0 & $1(4.5)$ \\
\hline Urinary frequency $(\mathbf{D} / \mathbf{N})$ & $9(40.9)$ & 0 & $1(4.5)$ & $1(4.5)$ & 0 \\
\hline Urgency & $6(27.2)$ & 0 & 0 & 0 & 0 \\
\hline Urgency incontinence & $6(27.2)$ & 0 & 0 & 0 & 0 \\
\hline Stress urinary incontinence & $5(22.7)$ & $1(4.5)$ & $1(4.5)$ & 0 & 0 \\
\hline Dribbling & $3(13.6)$ & 0 & 0 & 0 & 0 \\
\hline Incomplete void & $14(63.6)$ & 0 & 0 & 0 & 0 \\
\hline Poor urinary stream & $3(13.6)$ & 0 & $1(4.5)$ & $1(4.5)$ & 0 \\
\hline Constipation & $8(36.4)$ & $2(9)$ & $1(4.5)$ & $1(4.5)$ & $1(4.5)$ \\
\hline Feeling of discomfort per vaginum & $3(13.6)$ & 0 & 0 & 0 & 0 \\
\hline Backache & $5(22.7)$ & 0 & 0 & $1(4.5)$ & 0 \\
\hline
\end{tabular}

Table 2: Grading of prolapse preoperatively and during follow-up.

\begin{tabular}{|c|c|c|c|c|c|c|}
\hline Prolapse & Grade 0 & Grade 1 & Grade 2 & Grade 3 & Grade 4 & Total \\
\hline \multicolumn{7}{|c|}{ Before surgery $N=44$ (\%) } \\
\hline Cystocoele & 0 & 0 & $6(27.2)$ & $11(50)$ & $5(22.7)$ & 22 \\
\hline Uterine descent & $2(20)$ & $1(10)$ & $3(30)$ & $4(40)$ & 0 & 10 \\
\hline Vault prolapse & $1(8.3)$ & $1(8.3)$ & $1(8.3)$ & $5(41.6)$ & $4(33.3)$ & 12 \\
\hline Rectocoele & $12(54.5)$ & $8(36.3)$ & $2(9)$ & 0 & 0 & 22 \\
\hline Enterocoele & $9(40.9)$ & $7(31.8)$ & $2(9)$ & $1(4.5)$ & $3(13.6)$ & 22 \\
\hline \multicolumn{7}{|c|}{ After one week $N=44(\%)$} \\
\hline Cystocoele & $18(81.8)$ & $4(18.1)$ & 0 & 0 & 0 & 22 \\
\hline Vault prolapse & $22(100)$ & 0 & 0 & 0 & 0 & 22 \\
\hline Rectocoele & $18(81.8)$ & $4(18.1)$ & 0 & 0 & 0 & 22 \\
\hline Enterocoele & $21(95.4)$ & $1(4.5)$ & 0 & 0 & 0 & 22 \\
\hline \multicolumn{7}{|c|}{ After three months $\mathrm{N}=44(\%)$} \\
\hline Cystocoele & $18(81.8)$ & $4(18.1)$ & 0 & 0 & 0 & 22 \\
\hline Vault prolapse & $22(100)$ & 0 & 0 & 0 & 0 & 22 \\
\hline Rectocoele & $18(81.8)$ & $4(18.1)$ & 0 & 0 & 0 & 22 \\
\hline Enterocoele & $21(95.4)$ & $1(4.5)$ & 0 & 0 & 0 & 22 \\
\hline \multicolumn{7}{|c|}{ After six months $N=44(\%)$} \\
\hline Cystocoele & $18(81.8)$ & $4(18.1)$ & 0 & 0 & 0 & 22 \\
\hline Vault prolapse & $22(100)$ & 0 & 0 & 0 & 0 & 22 \\
\hline Rectocoele & $18(81.8)$ & $4(18.1)$ & 0 & 0 & 0 & 22 \\
\hline Enterocoele & $21(95.4)$ & $1(4.5)$ & 0 & 0 & 0 & 22 \\
\hline \multicolumn{7}{|c|}{ After twelve months $\mathrm{N}=44(\%)$} \\
\hline Cystocoele & $17(77.2)$ & $4(18.1)$ & $1(4.5)$ & 0 & 0 & 22 \\
\hline Vault prolapse & $22(100)$ & 0 & 0 & 0 & 0 & 22 \\
\hline Rectocoele & $18(81.8)$ & $4(18.1)$ & 0 & 0 & 0 & 22 \\
\hline Enterocoele & 21(95.4) & $1(4.5)$ & 0 & 0 & 0 & 22 \\
\hline
\end{tabular}

Table 3: QoL scale scores before and after surgery.

\begin{tabular}{|llllll|}
\hline Assessment & Before surgery & At one week & At 3 months & At 6 months & At 12 months \\
\hline POPDI 6 & 39 & 2 & 1.5 & 1.5 & 1.5 \\
\hline UDI 6 & 26 & 2 & 1.5 & 1.4 & 2 \\
\hline
\end{tabular}




\section{DISCUSSION}

Cystocele repair has been a challenge to pelvic floor surgeons. Cystocele is known to occur as a result of a central or lateral defect. The central defect has been known to account for 5 to $15 \%$ of cystocele occurrences, and the lateral defect for 70 to $80 \% .{ }^{9,10}$ However, the defects may be present simultaneously. ${ }^{11,12}$ Many surgical procedures have been described for cystocele repair. The surgical approach can be either vaginal or abdominal. The 3 basic techniques for cystocele repair are anterior colporrhaphy, anterior colporrhaphy with graft, and paravaginal repair which may be done vaginally, abdominally and laproscopically.

There is no consensus on the best treatment for the cystocoele surgery till date. The technique of anterior colporrhaphy was first described in 1913. Since then, it has undergone many modifications. Low sample size, variable definition of anterior colporrhaphy, short follow-up and studies not using the standard POP-Q system for the evaluation of the patients pose some limitations of the studies done for anterior colporrhaphy. The success rates thus reported are not homogenous and are poorly comparable. Studies by Glazener et al, Weber et al and Sand et al on colporrhaphy reported success rate of 37$84 \%$ with a follow-up of less than two years. ${ }^{13-15}$ Two randomised control studies by Allègre et al and Colombo report long term outcomes with mixed results with less sample sizes and a success rate of $33 \%$ at 5-8 years in only 36 women. ${ }^{16,17}$

Biologic and synthetic mesh were then introduced to improve surgical success rates of native tissue repair in anterior colporrhaphy. Both of these had no significantly higher success rate. Moreover, they have a higher complication rate and use of biologic material adds to further morbidity. ${ }^{13,16,18,19}$

Lastly, slings came into force for the anterior vaginal wall repair via the vaginal and abdominal routes. These also fair well with success rate of $43-100 \%$. The abdominal route involved greater morbidity and longer operating time. ${ }^{20,21}$

So, to decrease the morbidity and with comparable success rate minimal invasive laproscopic surgery came into force. This includes laproscopic paravaginal repair and the laproscopic mesh repair.

The advantages of minimal invasive laproscopic surgery are sharper delineation of anatomy, better dissection of anterior and posterior pelvic spaces, and minimal blood loss which outweigh the morbidity of laparotomy and extreme complications in vaginal paravaginal repair. ${ }^{22,23}$ Other advantages of laproscopic surgery includes - it allows deeper obliteration of cul-de-sac, greater strength, recurrence is less and complications like ureter and bowel injury are minimal due to better visualization. The completeness of the surgery can be judged immediately by per vaginum palpation and if needed can be corrected intraoperatively. The restoration of sharper lateral sulci and achievement of adequate vaginal length is done without any visible suture material or any vaginal incisions. ${ }^{24}$

In patients with advanced prolapse (stage III and beyond), restoration of anatomy and function usually necessitates more than one repair: concomitant posterior, apical, and enterocele repairs are usually required. The goal of cystocele repair is to restore the normal anatomical position of the bladder, which is located on the upper side of the imaginary line between the bilateral ischio-pubic ramus. ${ }^{25}$ To achieve this goal, we placed three polypropylene sutures laterally in the Cooper's ligament and posteriorly on the anterior surface of the cervix or the vaginal vault to create strengthened support for the bladder. We could see the elevated bladder neck by cystoscopy after taking the sutures in the anterior vaginal wall, which suggests elevation of the relaxed and elongated posterior floor of the bladder.

The success rate of abdominal paravaginal repair of cystocele has been reported between 75 and $97 \%$ in various studies. ${ }^{8}$ We showed an intraoperative correction of $\leq$ grade 1 with good results. Willison et al in their study described a success rate of $98.6 \%$ for restoration of paravaginal sulci. They reported that correcting lateral cystocele relieved the symptoms in majority of their patients with combined defects. ${ }^{26}$ We also report similar results in our study.

There are no randomised studies that demonstrate the higher efficacy of laproscopic paravaginal repair over other methods of repair. Hosni et al compared vaginal, abdominal and laparoscopic approaches and showed similar results with both the repairs. In their study, they reported that the laparoscopic group had no advantage over vaginal and abdominal repairs with prolonged operative time and extended hospital stay in the laproscopic group. The mean duration of paravaginal cystocele only repair in our study was 45 minutes. Moreover, the postoperative recovery was quicker following the laproscopic surgery.

Willison et al reported operative time from 50 to 255 minutes and hospital stay of 2-17 days. We had operative time of 80-240 minutes. ${ }^{26}$ The hospital stay in our study was 2-5 days. Duraisamy et al reported similar operative time of 90-220 min with average hospital stay of 2-3 days. $^{27}$

We used the technique of approximating the vagina and pubocervical fascia to Cooper's ligament. It was simple and effective. Willison et al reported anatomical cure rate of $76 \%$ with a similar technique. ${ }^{26}$ Bedford et al described the technique of approximating the vagina with both ATFP and Cooper's ligament. ${ }^{28}$ Our results of using the Cooper's ligament alone as an anchoring support were also good.

The occurrence of postoperative SUI after cystocele repair has been underreported. The postoperative mild stress 
urinary incontinence in one of our patients was probably due to overcorrection. ${ }^{27}$

Our technique demonstrates a high objective and subjective cure rate at 12 months follow-up, avoiding the use of synthetic material or autologous tissues. The main recurrences were low grade and didn't required reintervention. The best part of our study was the proper clinical examination and pre-operative assessment.

The limitations of our study are smaller study group and only twelve months follow-up. Larger studies with longer follow-up and randomised controlled trials will add further to future research. Still our study adds at least a pinch to the larger sea.

\section{CONCLUSION}

Laproscopic paravaginal cystocoele repair is safe, effective and an easy procedure with good results. The procedure is easy to learn and master with low recurrence rates.

Funding: No funding sources Conflict of interest: None declared

Ethical approval: The study was approved by the Institutional Ethics Committee

\section{REFERENCES}

1. Starič KD, Bukovec P, Zore A, Lukanović A. Recurrent pelvic organ prolapse: a case report. Urogynaecologia. 2017;30:194.

2. Hoffman B, Schorge J, Schaffer J, Halvorson J, Bradshaw K, Cunningham F. Williams gynecology (2nd ed.). New York: McGraw-Hill Medical. 2012;647-53.

3. Hamid R, Losco G. Pelvic Organ Prolapse-Associated Cystitis. Curr Bladder Dysfunct Rep. 2014;9(3):17580.

4. Deng DY, Rutman M, Rodriguez L, Raz S. Correction of cystocele. BJU Int. 2005;96(4):691-709.

5. Barber MD, Maher C. Epidemiology and outcome assessment of pelvic organ prolapse. Int Urogynecol J. 2013;24(11):1783-90.

6. Choi KH, Hong JY. Management of pelvic organ prolapse. Korean J Urol. 2014;55(11):693-702.

7. Persu C, Chapple CR, Cauni V, Gutue S, Geavlete P. Pelvic Organ Prolapse Quantification System (POPQ) - a new era in pelvic prolapse staging. J Med Life. 2011;4(1):75-81.

8. Brubaker L, Maher C, Jacquetin B. Surgery for pelvic organ prolapse. Female Pelvic Med Reconstr Surg. 2010;16(1):9-19.

9. Kobashi KC, Leach GE, Chon J, Govier FE. Continued multicenter followup of cadaveric prolapse repair with sling. J Urol. 2002;168(5):2063-8.

10. Richardson AC, Edmonds PB, Williams NL. Treatment of stress urinary incontinence due to paravaginal fascial defect. Obstet Gynecol. 1981;57(3):357-62.

11. Safir MH, Gousse AE, Rovner ES, Ginsberg DA, Raz S. 4-Defect repair of grade 4 cystocele. J Urol. 1999;161(2):587-94.

12. Rodríguez LV, Bukkapatnam R, Shah SM, Raz S. Transvaginal paravaginal repair of high-grade cystocele central and lateral defects with concomitant suburethral sling: report of early results, outcomes, and patient satisfaction with a new technique. Urology. 2005;66(5):57-65.

13. Glazener CM, Breeman S, Elders A, Hemming C, Cooper KG, Freeman RM, et al. Mesh, graft, or standard repair for women having primary transvaginal anterior or posterior compartment prolapse surgery: two parallel-group, multicentre, randomised, controlled trials (PROSPECT). Lancet. 2017;389(10067):381-92.

14. Weber AM, Walters MD, Piedmonte MR, Ballard LA. Anterior colporrhaphy: a randomized trial of three surgical techniques. Am J Obstet Gynecol. 2001;185(6):1299-304.

15. Sand PK, Koduri S, Lobel RW, Winkler HA, Tomezsko J, Culligan PJ, Goldberg R. Prospective randomized trial of polyglactin 910 mesh to prevent recurrence of cystoceles and rectoceles. Am J Obstet Gynecol. 2001;184(7):1357-62.

16. Allègre L, Callewaert $\mathrm{G}$, Alonso S, Cornille A, Fernandez H, Eglin G, de Tayrac R. Long-term outcomes of a randomized controlled trial comparing trans-obturator vaginal mesh with native tissue repair in the treatment of anterior vaginal wall prolapse. Int Urogynecol J. 2020;31(4):745-53.

17. Colombo M, Vitobello D, Proietti F, Milani R. Randomised comparison of Burch colposuspension versus anterior colporrhaphy in women with stress urinary incontinence and anterior vaginal wall prolapse. BJOG. 2000;107(4):544-51.

18. Handel LN, Frenkl TL, Kim YH. Results of cystocele repair: a comparison of traditional anterior colporrhaphy, polypropylene mesh and porcine dermis. J Urol. 2007;178(1):153-6.

19. Balzarro M, Rubilotta E, Porcaro AB, Trabacchin N, Sarti A, Cerruto MA, et al. Long-term follow-up of anterior vaginal repair: A comparison among colporrhaphy, colporrhaphy with reinforcement by xenograft, and mesh. Neurourol Urodyn. 2018;37(1):278-83.

20. Dmochowski RR, Zimmern PE, Ganabathi K, Sirls L, Leach GE. Role of the four-corner bladder neck suspension to correct stress incontinence with a mild to moderate cystocele. Urology. 1997;49(1):35-40.

21. Cormio L, Mancini V, Liuzzi G, Lucarelli G, Carrieri G. Cystocele Repair by Autologous Rectus Fascia Graft: the Pubovaginal Cystocele Sling. J Urol. 2015;194(3):721-7.

22. Ganatra AM, Rozet F, Sanchez-Salas R. The current status of laparoscopic sacrocolpopexy: a review. Eur Urol. 2009;55(5):1089-105. 
23. Kdous M, Zhioua F. 3-year results of transvaginal cystocele repair with transobturator four-arm mesh: a prospective study of 105 patients. Arab J Urol. 2014;12(4):275-84.

24. Rosen DM, Shukla A, Cario GM. Is hysterectomy necessary for laparoscopic pelvic floor repair? A prospective study. J Minim Invasive Gynecol. 2008;15(6):729-34.

25. Ng CC, Chong CY. The effectiveness of transvaginal anterior colporrhaphy reinforced with polypropylene mesh in the treatment of severe cystoceles. Ann Acad Med Singap. 2006;35(12):875-81.

26. Price N, Jackson SR. Advances in laparoscopic techniques in pelvic reconstructive surgery for prolapse and incontinence. Maturitas. 2009;62(3):276-80.

27. Duraisamy KY, Balasubramaniam D, Kakollu A, Chinnusamy P, Periyasamy K. A Prospective Study of Minimally Invasive Paravaginal Repair of Cystocele and Associated Pelvic Floor Defects: Our Experience. J Obstet Gynaecol India. 2019;69(1):82-88.

28. Bedford ND, Seman EI, O'shea RT. Long-term outcomes of laparoscopic repair of cystocoele. Aust N Z J Obstet Gynaecol. 2015;55(6):588-92.

Cite this article as: Gosavi AD, Dhangar SP. A prospective study of laproscopic paravaginal repair of cystocoele: our experience. Int J Reprod Contracept Obstet Gynecol 2021;10:3472-7. 